\title{
MODELOWANIE NORM PRACOCHŁONNOŚCI W PLANOWANIU MONOLITYCZNYCH ROBÓT BETONOWYCH
}

\author{
Anna Krawczyńska-Piechna ${ }^{\bowtie}$ \\ Wydział Budownictwa, Mechaniki i Petrochemii, Politechnika Warszawska, Płock
}

\begin{abstract}
STRESZCZENIE
Planowanie realizacji monolitycznych robót betonowych wymaga analizy nakładów pracy robót zbrojarskich i deskowaniowych. Analizy tej można dokonać, korzystając z własnego doświadczenia, baz wiedzy producentów deskowań oraz polskich lub zagranicznych katalogów nakładów rzeczowych. Różnorodność tych źródeł prowadzi do pytania: które z nich pozwala wyznaczyć realne wielkości nakładów? W pracy zawarto analizę dostępnych źródeł wiedzy o nakładach rzeczowych oraz dokonano syntetycznego przeglądu czynników mających wpływ na pracochłonność robót wykonywanych w technologii MBB. Następnie zaprezentowano strukturę nowej, inteligentnie zarządzanej bazy wiedzy o normach czasu pracy robót betonowych. Do uczenia się bazy i predykcji pracochłonności zaproponowano wykorzystanie zagregowanych (np. metodą boostingu) klasyfikatorów i tej metodzie statystycznej podporządkowano strukturę bazy.
\end{abstract}

Słowa kluczowe: roboty betonowe, szacowanie pracochłonności robót, deskowanie, inteligentne bazy danych

\section{WSTĘP}

Warunkiem rzetelnego zaplanowania robót budowlanych jest w pierwszej kolejności posiadanie wiarygodnych norm procesów pracy. Prowadzenie analizy nakładów rzeczowych na wykonanie robót i kosztów ich realizacji wymaga sparametryzowanego opisu procesów pracy oraz znajomości charakterystyk techniczno-eksploatacyjnych maszyn i urządzeń. Powszechne we wpółczesnym budownictwie procesy monolitycznego budownictwa betonowego (MBB) cechują się kompleksową mechanizacją i dużym zaangażowaniem konstrukcji pomocniczych, $\mathrm{z}$ jednoczesną koniecznością przestrzegania reżimów technologicznych.

Strukturyzacja i badanie procesów pracy związanych z realizacją obiektów w technologii monolitycznego buownictwa betonowego były przedmiotem badań Kopera (2013), Marcinkowskiego i Kopera (2014) oraz Krawczyńskiej-Piechna (2015). Badania te dotyczyły zarówno normowania procesów pracy w tej technologii, jak i analizy pracy deskowań systemowych w kontekście ich efektywnego wykorzystania na budowie. W toku tych badań dostrzeżono konieczność weryfikacji powszechnie stosowanych katalogów nakładów rzeczowych pod kątem pracochłonności robót - to właśnie jej określenie ma najistotniejsze znaczenie dla rzetelnego zaplanowania przebiegu relizacji robót. Niestety, mając na względzie stosowane współcześnie środki mechanizacji pracy i rozwiązania technologiczne, należy stwierdzić, że procesy monolitycznego budownictwa betonowego nie zostały dostatecznie znormowane w krajowych katalogach nakładów rzeczowych (KNR). Dotyczy to w szczególności stosowania systemowych deskowań i konstrukcji wsporczych, jak również stosowania

${ }^{\bowtie}$ Anna.Krawczynska@pw.edu.pl 
prefabrykowanego zbrojenia. W tej sytuacji planujący roboty może dokonać analizy nakładów pracy, wykorzystując np. własne doświadczenie lub badania, trudno dostępne bazy wiedzy producentów systemów deskowań, powszechnie dostępne, lecz nieprecyzyjne polskie katalogi nakładów rzeczowych bądź odpowiednie katalogi zagraniczne. Różnorodność tych źródeł prowadzi do pytania: które z nich pozwala wyznaczyć realne dla konkretnej sytuacji wielkości nakładów na wykonanie robót?

W pracy syntetycznie porównano dostępne źródła wiedzy o nakładach. Zaproponowano także koncepcję struktury nowej bazy wiedzy oraz mechanizm jej funkcjonowania, tak by w przyszłości szacowanie nakładów pracy odpowiadało relanym sytuacjom budowlanym.

\section{OCENA DOSTĘPNYCH ŹRÓDEŁ WIEDZY O NAKŁADACH RZECZOWYCH NA WYKONANIE ROBÓT BETONOWYCH}

Przystępując do planowania robót, informacje o normach i nakładach pracy można pozyskiwać z różnych katalogów, np. powszechnie funkcjonujących na rynku polskim katalogów nakładów rzeczowych (KNR), ich niemieckich „odpowiedników” - tablic ARH (niem. Arbeitszeit Richtwerte Tabellen) bądź innych, np. amerykańskich RSMeans Labor Rates.

Panuje powszechne przekonanie, że katalogi KNR umożliwiają planowanie zarówno rzeczowe, jak i kosztowe realizacji budowy dla większości asortymentów robót. W przypadku prac realizowanych $\mathrm{w}$ technologii MBB z zastosowaniem deskowań systemowych (np. katalogi KNR 0-20, NNRNKB 202, KNR-W-2 02) nie jest to już tak oczywiste. Przede wszystkim dlatego, że pozycje katalogowe są scalone do poziomu całego elementu betonowego i obejmują szereg operacji: przygotowanie kompletu elementów deskowania, wytyczenie osi deskowania, montaż elementów deskowania, usztywnienie konstrukcji deskowania, założenie pomostu roboczego, rektyfikację deskowania, ułożenie i zagęszczenie betonu, demontaż konstrukcji usztywniającej i rozbiórkę deskowania, oczyszczenie i konserwację płyt środkiem antyadhezyjnym, ułożenie i posegregowanie elementów deskowania. W takiej sytuacji określenie nakładów pracy dla poszczególnych elementów procesu technologicznego jest niemożliwe.

Kolejnym ograniczeniem przydatności KNR-ów do planowania jest ich merytoryczny zakres rzeczowy - nie obejmują one wszystkich stosowanych współcześnie technologii, np. stropowych deskowań panelowych czy stolikowych, podpór wieżowych, panelowych deskowań słupowych czy wielkoformatowych deskowań ściennych. W zakresie robót zbrojarskich brakuje pozycji (tablic) opisujących montaż zbrojenia prefabrykowanego i półprefabrykowanego. Nie podaje się również nakładów pracy na wykonanie np. otworów ściennych, szybów i szachtów czy ścian łukowych.

W tej sytuacji planujący roboty może skorzystać z katalogów zagranicznych, np. ARH. Znajdzie w nich znacznie szerszy asortyment technologii wykonania robót. Wartości zawarte w ARH uwzględniają m.in.: stopień skomplikowania i wielkość wykonywanej konstrukcji, konieczność wykonania detali (np. zmiana przekroju konstrukcji - rys. 1, wykonanie bruzd i osadzenie szyn ze zbrojeniem odginanym) oraz krotność wykonania elementu, co wiąże się z ograniczeniem prac demontażowych i przenoszeniem częściowo scalonych deskowań na inne działki.

Korzystając z tabel ARH, pamiętać należy, że podane w nich normy zostały odniesione do tzw. brygady technologicznej (niem. Soll-Arbeitsgruppe) i de facto określają normy zużycia czasu pracy. Oczywiście skład i liczebność brygady technologicznej są zdefiniowane w opisie tablic, odrębnie dla każdego rodzaju robót. Tego typu podejście w kontekście planowania rzeczowego i czasowego robót jest znaczącym uproszczeniem i może być stosowane wprost także $\mathrm{w}$ warunkach polskich. Z kolei z punktu widzenia szczegółowej kalkulacji kosztorysowej nie jest możliwe płynne zastosowanie norm ARH. 


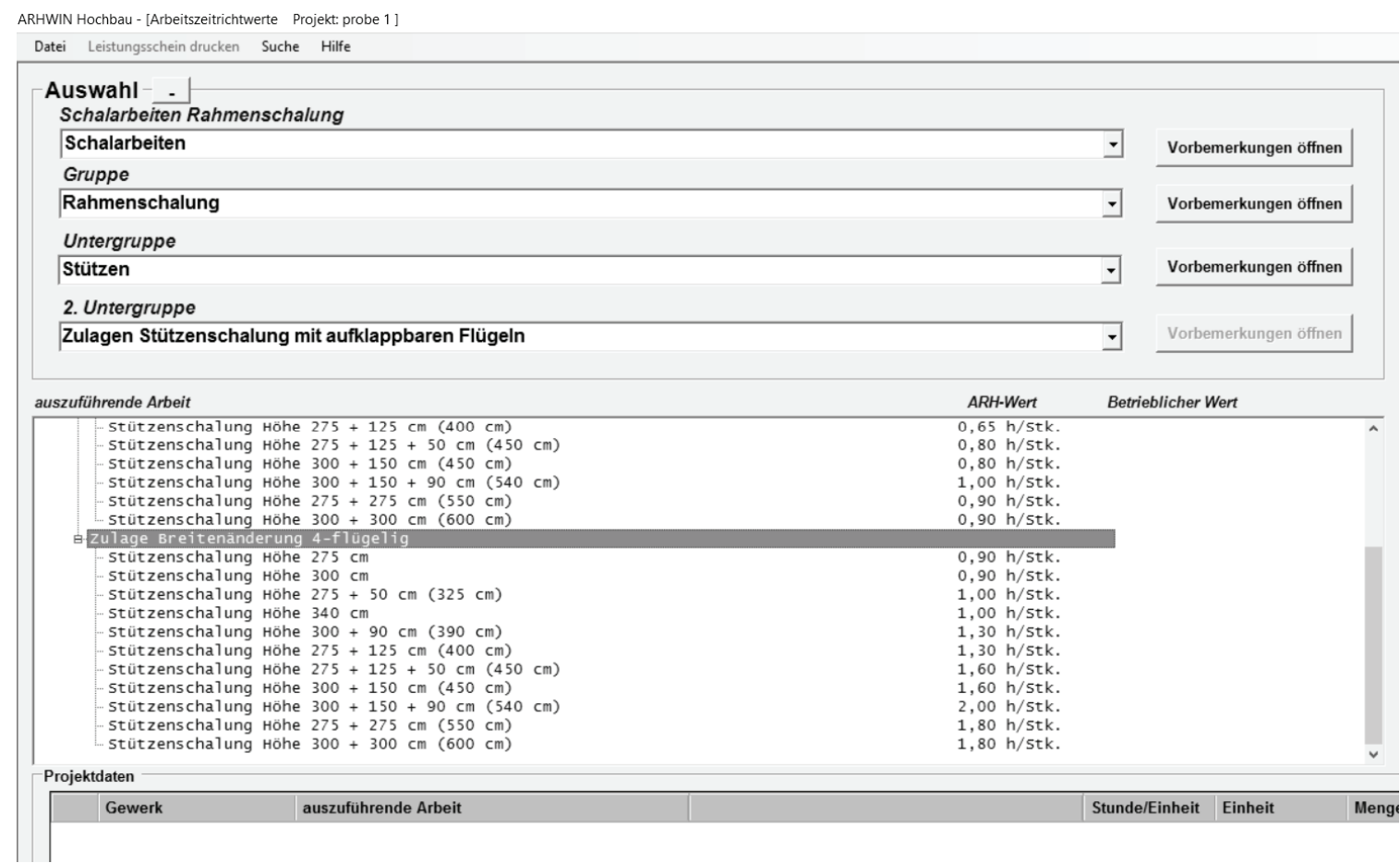

Rys. 1. Tabela ARH w wersji komputerowej - widok okna programu ARH-Win. Na rysunku pokazano wartości dodatków za zmianę przekroju słupa w deskowaniu panelowym w zależności od wysokości słupa

Fig. 1. ARH Tables - ARH-Win application window view. The Figure shows the values of additions due to a change in a column cross section's dimensions in relation to column height

\section{KONCEPCJA „INTELIGENTNEGO" MODELOWANIA INFORMACJI O PRACOCHŁONNOŚCI ROBÓT W TECHNOLOGII MBB}

\section{Idea opracowywanej metody modelowania}

Analizując stosowane w różnych krajach podejścia i metodykę oceny pracochłonności robót betonowych, można stwierdzić, że do wiarygodnego planowania robót w technologii MBB konieczne jest rozpatrywanie norm i nakładów pracy na poziomie elementów procesu technologicznego. Oznacza to konieczność dekompozycji dotychczas stosowanych norm KNR i zbudowania nowej bazy wiedzy, gromadzącej informacje o realnych, tj. możliwych do uzyskania w określonych warunkach budowy normach czasu pracy dla robót zbrojarskich, deskowaniowych i betonowych. Wraz z budowaną bazą współpracować powinien inteligentny menedżer, dzięki któremu możliwe będzie uczenie bazy, dokonywanie predykcji na etapie planowania robót oraz dodawanie nowych danych, pochodzących z pomiarów dokonywanych in situ w trakcie realizacji prac. Schemat przepływu informacji w bazie przedstawia rysunek 2 .

Stworzenie bazy informacji wymaga w pierwszej kolejności zdeterminowania jej struktury. Niezbędne w tym celu jest określenie czynników wpływających na pracochłonność robót deskowaniowych i zbrojarskich. 


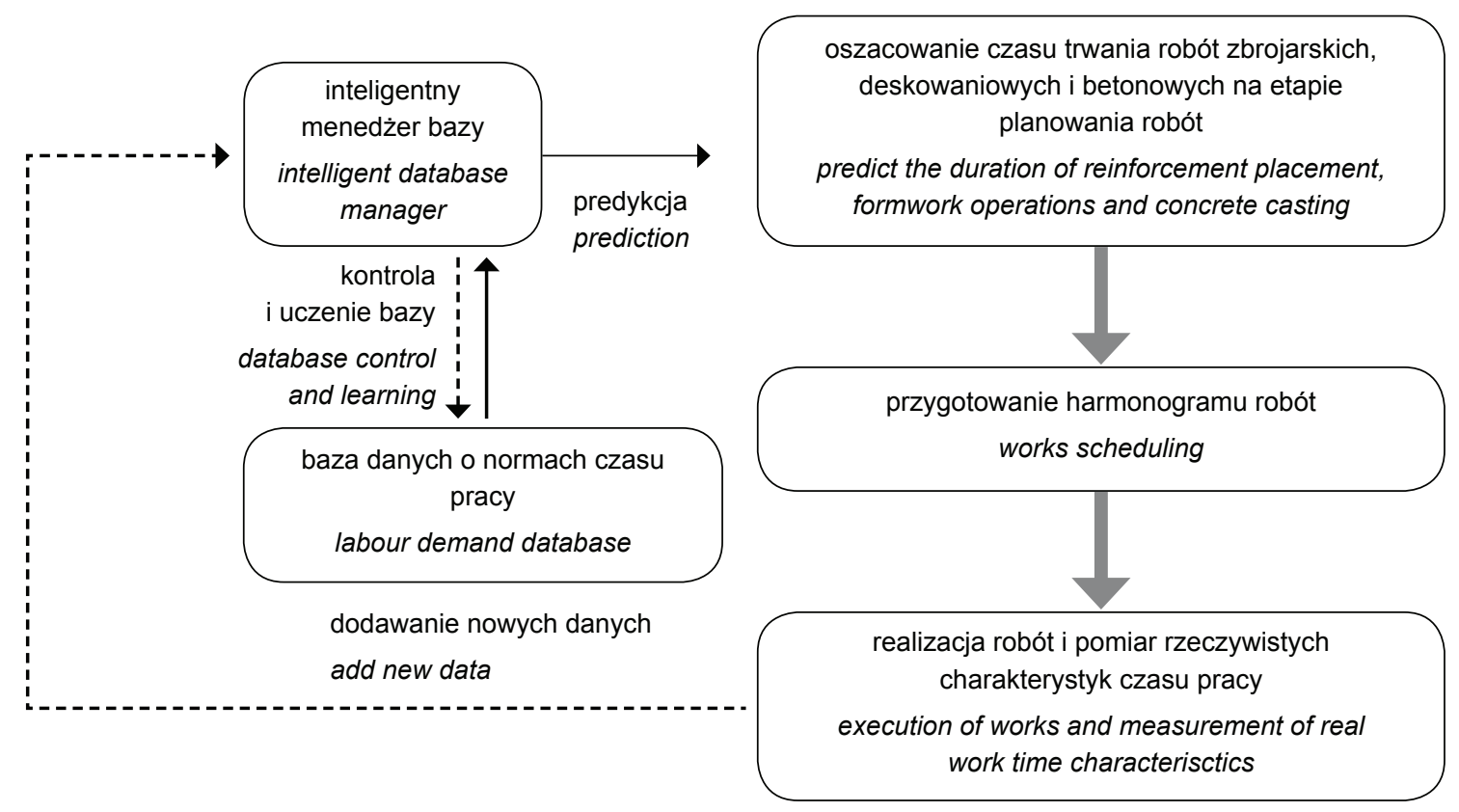

Rys. 2. Schemat przepływu informacji w inteligentnie zarządzanej bazie danych o normach czasu pracy

Fig. 2. Information flow in an intelligently managed labour demand database - a scheme

\section{Przegląd czynników wpływających na pracochłonność robót wykonywanych w technologii MBB}

Analiza czynników, które mają wpływ na szeroko rozumianą jakość i efektywność prowadzenia robót betonowych, była i jest szeroko poruszana w literaturze światowej. Dwoma dominującymi zagadnieniami w rozpatrywanym obszarze badawczym są: analiza możliwości predykcji pracochłonności, a w zasadzie wydajności (ang. productivity) robót wykonywanych w technologii MBB oraz badanie i ocena technologiczności konstrukcji betonowych wraz z analizą jej wpływu na tempo i jakość wykonywanych robót. Prowadzenie tego typu badań jest jak najbardziej uzasadnione - wymaga tego zarówno wysoko rozwinięta kultura budowania w krajach anglojęzycznych, azjatyckich i arabskich, jak i samo budownictwo wysokie i wysokościowe, przy którego realizacji kluczową rolę odgrywa sprawna organizacja robót i utrzymanie dużego tempa prac przy przechodzeniu na kolejne działki robocze.

Pierwszy z wymienionych problemów był w ostatnich latach przedmiotem badań Portasa i Rizka (1997), Proverbsa, Holta i Olomolayiego (1999), Songa i AbouRizka (2008), Moselhiego i Khana (2010) oraz Mine'a, Waiego, Lima i Kanga (2015), którzy analizowali statystycznie czynniki determinujące tempo montażu i demontażu deskowań oraz realizacji prac betonowych. Na podsatwie tych badań wśród czynników istotnie wpływających na pracochłoność robót wykonywanych w technologii MBB wyróżnić można 3 zasadnicze grupy:

- czynniki związane z geometrią realizowanego obiektu, m.in. wysokość kondygnacji, wielkość działek roboczych,

- czynniki związane z predyspozycjami pracowników, m.in. wiek i staż zawodowy,

- czynniki związane bezpośrednio z deskowaniem bądź zbrojeniem, m.in. typ, jakość i ilość użytego deskowania oraz ilość, średnica i stopień prefabrykacji zbrojenia. 
Z kolei według Peuriffoya i Oberlendera (2011) determinantą sprawnego prowadzenia robót betonowych jest przede wszystkim technologiczność (ang. constructability, buildability) realizowanej konstrukcji. Racjonalnie zaprojektowane elementy konstrukcji, a zatem proste w realizacji, w miarę możliwości zunifikowane, podobne lub powtarzalne, o wymiarach lub modułach dostosowanych do typowych deskowań i sprzętów wykorzystywanych przy ich wznoszeniu, przyczyniają się do wzrostu wydajności robót w technologii MBB. Dotyczy to zarówno samych elementów konstrukcyjnych, jak i poszczególnych jej komponentów, np. zbrojenia. Zależność pomiędzy pracochłonnością a technologicznością badali i modelowali m.in. Jergeas i Put (2001) oraz Jarkas (2010a, 2010b).

Korzystając zarówno z powyższych doświadczeń, jak i własnych studiów i analiz, zaproponowano włączenie wyżej wymienianych czynników do modelowania informacji o pracochłonności robót betonowych.

\section{Propozycja modelu bazy wiedzy o pracochłonności robót i jej menedżera}

Przedmiotową bazę proponuje się zbudować według następującego modelu: dany będzie zbiór atrybutów - parametrów wejściowych: $A=\left\{a_{1}, \ldots, a_{n}\right\}$ oraz zbiór przypisywanych im decyzji: $D=\left\{d_{1}, \ldots, d_{m}\right\}$. Oszacowanie informacji o pracochłonności robót polegać będzie na sklasyfikowaniu, tj. przydzieleniu decyzji „przychodzącemu" obiektowi $y$. Obiekt opisany zostanie za pomocą atrybutów ze zbioru $A=\left\{a_{i}(y)=b_{i}\right\}$, gdzie $b_{i}$ są znane, kalsyfikacja zaś nastapi na podstawie zadanych wartości $b_{i}$. Odbywać się to będzie, tak jak w przypadku większości technik inteligentnych, w dwóch etapach:

- etapie uczenia (trenowania i budowy modelu), w którym znajduje się reguły klasyfikacyjne na podstawie wybranego losowo zbioru uczącego,

- klasyfikacji obiektu $y$ na podstawie znalezionej charakterystyki klas.

Do uczenia i predykcji pracochłonności proponuje się wykorzystanie zagregowanych metodą boostingu klasyfikatorów (tzw. rodziny klasyfikatorów, ang. classifier ensembles). Dlaczego właśnie takie narzędzie? Rodziny (zespoły) klasyfikatorów (por. Gatnar, 2008; Shin, Kim, Yang, Cho i Kang, 2008; Shin i in., 2009) budowane są na podstawie klasyfikatorów bazowych (np. klasyfikator liniowy, metoda najbliższych sąsiadów, metoda wektorów nośnych, drzewa decyzyjne). Posiadają zadziwiająco dobre własności w przypadku, gdy kolejny klasyfikator obarczony jest dużym ryzykiem całkowitym, jednak mniejszym niż ryzyko całkowite klasyfikatora losowego (z klasyfikatorem losowym mamy do czynienia, gdy wybór klasy jest dokonywany losowo). Podejście wielomodelowe wykorzystuje się także w przypadku, gdy zbiór danych jest mały, co grozi zbyt dobrym dopasowaniem pojedynczego modelu do danych. Przy zastosowaniu zagregowanych klasyfikatorów proces klasyfikacji nie jest więc zależny od wielkości próby uczącej, co w przypadku badania procesów technologicznych na budowach może mieć kluczowe znaczenie $\mathrm{z}$ uwagi na ograniczenia w pozyskiwaniu danych.

Dla opisywanej bazy proponowane parametry wejściowe, rozpatrywane w analizie pracochłonności robót wykonywanych w technologii MBB, zebrano w tabeli 1.

$\mathrm{Z}$ uwagi na dyskryminacyjny charakter wybranego narzędzia zarządzającego bazą wartość decyzji powinna być podana w skali nominalnej. Proponuje się, by był to iloraz wyrażający stosunek zmierzonej w warunkach in situ wartości normy czasu pracy do wartości normy bazowej, zaczerpniętej z katalogów ARH. Dokonywanie predykcji przy użyciu zaproponowanego narzędzia polegać będzie zatem na oszacowaniu, czy i w jakim przedziale procentowym należy zmodyfikować normę podstawową. 
Krawczyńska-Piechna, A. (2017). Modelowanie norm pracochłonności w planowaniu monolitycznych robót betonowych. Acta Sci. Pol. Architectura, 16 (2), 13-19. doi: 10.22630/ASPA.2017.16.2.02.

Tabela 1. Propozycja parametrów wejściowych do inteligentnie zarządzanej bazy wiedzy

Table 1. Input data for an intelligently managed database

\begin{tabular}{|c|c|c|c|}
\hline \multirow{2}{*}{$\begin{array}{l}\text { Parametr wejściowy } \\
\text { Input }\end{array}$} & \multicolumn{3}{|c|}{ Wartości parametru wejściowego - Input values } \\
\hline & $\begin{array}{l}\text { roboty deskowaniowe } \\
\text { formwork operations }\end{array}$ & $\begin{array}{l}\text { roboty zbrojarskie } \\
\text { reinforcement placement }\end{array}$ & $\begin{array}{l}\text { roboty betonowe } \\
\text { concrete casting }\end{array}$ \\
\hline $\begin{array}{l}\text { Typ konstrukcji } \\
\text { Construction type }\end{array}$ & \multicolumn{3}{|c|}{$\begin{array}{l}\text { tarcza / płyta / belka / słup / fundament / inne } \\
\text { shield/ plate/ beam / column / foundation / others }\end{array}$} \\
\hline $\begin{array}{l}\text { Środki mechanizacji pracy } \\
\text { Mechanization of works }\end{array}$ & $\begin{array}{l}\text { brak / dźwig } \\
\text { none / crane }\end{array}$ & & $\begin{array}{l}\text { brak / pompa do betonu / kosz } \\
+ \text { żuraw / inne } \\
\text { none / concrete pump/ concrete } \\
\text { bucket + crane / others }\end{array}$ \\
\hline $\begin{array}{l}\text { Technologiczność elementu } \\
\text { konstrukcji } \\
\text { Structure's constructability }\end{array}$ & \multicolumn{3}{|c|}{$\begin{array}{l}\text { ocena w skali } 1-5 \\
\text { rating, scale } 1-5\end{array}$} \\
\hline $\begin{array}{l}\text { Kwalifikacje pracowników } \\
\text { Workers' skills }\end{array}$ & \multicolumn{3}{|c|}{$\begin{array}{l}\text { niskie / przeciętne / wysokie } \\
\text { low / average / high }\end{array}$} \\
\hline $\begin{array}{l}\text { Brygada } \\
\text { Crew }\end{array}$ & \multicolumn{3}{|c|}{$\begin{array}{l}\text { liczba pracowników } \\
\text { number of workers }\end{array}$} \\
\hline $\begin{array}{l}\text { Warunki prowadzenia robót } \\
\text { Site conditions }\end{array}$ & \multicolumn{3}{|c|}{$\begin{array}{c}\text { obojętne / utrudniające prowadzenie robót, wymagające szczególnych zachowań } \\
\text { indifferent / hampering or requiring specific behaviour }\end{array}$} \\
\hline $\begin{array}{l}\text { Stopień scalenia deskowania/ } \\
\text { zbrojenia } \\
\text { Degree of formwork/ } \\
\text { reinforcement consolidation }\end{array}$ & $\begin{array}{l}\text { deskowania prefabrykowane } \\
\text { scalone (np. stoliki stropowe, } \\
\text { scalone deskowania } \\
\text { szybowe) / deskowania } \\
\text { panelowe / deskowania } \\
\text { niescalone - scalane } \\
\text { w całości na budowie } \\
\text { pre-assembled formwork } \\
\text { (eg. table formwork, } \\
\text { shaft formwork) / panel } \\
\text { formwork / formwork } \\
\text { assembled on site }\end{array}$ & $\begin{array}{l}\text { zbrojenie całkowicie } \\
\text { sprefabrykowane / zbrojenie } \\
\text { częściowo sprefabrykowane } \\
\text { (pręty cięte i gięte } \\
\text { w zakładzie prefabrykacji, } \\
\text { scalane na budowie)/ } \\
\text { niesprefabrykowane (cięcie, } \\
\text { gięcie i wiązanie prętów } \\
\text { odbywa się na budowie) } \\
\text { pre-assembled reinforcement } \\
\text { / reinforcement partially pre- } \\
\text { assembled (only tied on site) } \\
\text { / reinforcement cut, bend and } \\
\text { tied on site. }\end{array}$ & $\begin{array}{l}\text { nie dotyczy } \\
\text { does not apply }\end{array}$ \\
\hline
\end{tabular}

\section{PODSUMOWANIE}

Planowanie nakładów reczowych, a w szczególności nakładów pracy dla robót wykonywanych w technologii MBB wymaga nie tylko znajomości uwarunkowań technologiczno-organizacyjnych prowadzenia robót, ale także umiejętności oceny tego, jaki jest wpływ tych uwarunkowań na tempo prowadzenia prac. Wobec braku jednolitych wytycznych i kompletnych katalogów norm nakłdów pracy w artykule zaproponowano alternatywne narzędzie do szacowania wartości norm czasu pracy w postaci inteligentnie zarządzanej bazy wiedzy. Zbudowany na podstawie zagregowanych klasyfikatorów menedżer bazy pozwala na etapie planowania robót ocenić, czy i w jakim zakresie konieczna jest modyfikacja katalogowych wartości norm czasu pracy w zależności od rzeczywistych warunków prowadzenia prac. Oczywiście do realizacji zaprezentowanego zamierzenia konieczne jest przeprowadzenie serii pomiarów pilotażowych na budowach i pozyskanie metodą ankietyzacji danych wejściowych do bazy, co będzie przedmiotem dalszych badań. 


\section{PIŚMIENNICTWO}

ARH - Tabellen. Rahmenschalung, Wände und Stützenschalung (2016). Zeittechnik-Verlag GmbH.

Gatnar, E. (2008). Podejście wielomodelowe w zagadnieniach dyskryminacji i regresji. Warszawa: Wydawnictwo Naukowe PWN.

Jarkas, A. M. (2010a). Buildability factors affecting formwork labour productivity of building floors. Canadian Journal of Civil Engineering, 37, 1383-1394.

Jarkas, A. M. (2010b). The impacts of buildability factors on formwork labour productivity of columns. Canadian Journal of Construction Engineering and Management, 16 (4), 471-483.

Jergeas G., i Put J. (2001). Benefits of constructability on construction projects. Journal of Construction Engineering and Management, 127(4), 281-290.

Koper, A. (2013). Normowanie procesów monolitycznego budownictwa betonowego na potrzeby planowania robót z uwzględnieniem niepewności danych. Rozprawa doktorska. Warszawa: Politechnika Warszawska.

Krawczyńska-Piechna, A. (2015). Interaktywna metoda planowania robót betonowych z analizq efektywności wykorzystania deskowań systemowych. Rozprawa doktorska. Warszawa: Politechnika Warszawska.

Marcinkowski, R. i Koper, A. (2014). Ocena i normowanie rozwiązań technologiczno-organizacyjnych procesów budowlanych. Budownictwo i Architektura, 13(4), 365-371.

Mine, N., Wai, S. H., Lim, T. C. i Kang, W. (2015). An Observational Study on the Productivity of Formwork in Building Construction. In $32^{\text {nd }}$ ISARC-2015 Proceedings, $1-8$. Oulu.

Moselhi, O. i Khan, Z. (2010). Analysis of Labour Productivity of Formwork Operations in Building Construction. Construction Innovation, 10 (3), 286-303.

Peurifoy, R. L. i Oberlender, G. D. (2011). Formwork for concrete structures. New York: McGraw-Hill.

Portas, J. i Rizk, S.A. (1997). Neural Network Model for Estimating Construction Productivity. Journal of Construction Engineering and Management, 123 (4), 399-410.

Proverbs, D. G., Holt, G. D. i Olomolaiye, P. O. (1999). Construction resource/method factors influencing productivity for high rise concrete construction. Construction Management and Economics, 17, 577-587.

Shin, Y., Kim, D. Y., Yang, S. W., Cho, H. H. i Kang, K. I. (2008). Decision support model using the AdaBoost algorithm to select formwork systems in high-rise building construction. In 25 th ISARC-2008 Proceedings, 644-649. Vilnius.

Shin, Y., Kim D. W, Kim J. Y., Kang, K. I., Cho M. Y. i Cho H. H. (2009). Application of AdaBoost to the retaining wall method selection in construction. Journal of Computing in Civil Engineering, 23, 188-192.

Song, L. i AbouRizk, S. M. (2008). Measuring and Modeling Labour Productivity Using Historical Data. Journal of Construction Engeneering and Management, 134 (10), 786-794.

\section{MODELING LABOUR RATES IN CONCRETE CONSTRUCTION PLANNING}

\section{SUMMARY}

To plan concrete works reliably it is necessary to analyse labour demands for all the technological operations, including reinforcement placement and formwork operations in particular. Such analyses can be made using planner's own experience, the data delivered by formwork producers, Polish or foreign catalouges of labour rates. Which of those provides the most reliable labour assessment? The paper describes different sources of information on labour rates for concrete works, including formwork and reinforcement operations. It also presents a brief review of factors influencing on labour productivity, as well as introduces a concept structure of a new, intelligently managed database applicable for labour prediction. Database learning and labour prediction is thought to be made using classifier ensembles.

Key words: concrete works, formwork, labour estimation, intelligent databases 